\title{
4-hydrazinobenzoic acid as a derivatizing agent for aldehyde analysis by HPLC-UV and CE-DAD
}

\section{A R T I C L E I N F O}

\section{Keywords:}

Carbonyl compounds

Derivatization

Sample preparation

Secondary ketamine

Schiff base

Volatile and semi-volatile extraction

\begin{abstract}
A B S T R A C T
Aldehydes are relevant analytes in a wide range of samples, in particular, food and beverages but also body fluids. Hydrazines can undergo nucleophilic addition with aldehydes or ketones giving origin to hydrazones (a group of stable imines) that can be suitably used in the identification of aldehydes. Herein, 4-hydrazinobenzoic acid (HBA) was, for the first time, used as the derivatizing agent in analytical methodologies using liquid chromatography aiming the determination of low-molecular aldehydes. The derivatization reaction was simultaneously performed along with the extraction process, using gas-diffusion microextraction (GDME), which resulted in a clean extract containing the HBA-aldehyde derivates. The corresponding formed imines were determined by both high-performance liquid chromatography (LC) with UV spectrophotometric detection (HPLCUV) and capillary electrophoresis with diode array detection (CE-DAD). HBA showed to be a rather advantageous derivatization reagent due to its stability, relatively high solubility in water and other solvents, high selectivity and sensibility, reduced impurities, simple preparation steps and applicability to different separation and/or different detection techniques. Limits of detections (LODs) of the optimized methodologies (in terms of time and $\mathrm{pH}$ among other experimental variables) were all below $0.5 \mathrm{mg} \mathrm{L}^{-1}$, using both instrumental techniques. Furthermore, for the first time, the HBA-aldehyde derivatives were analyzed by LC with mass spectrometry (LC-MS), demonstrating the possibility of identification by MS of each compound. The developed methodologies were also successfully applied in the analysis of formaldehyde and acetaldehyde in several alcoholic beverages. This was also the first time GDME was combined with CE, showing that it can be a valuable sample preparation tool for electrophoresis, in particular by eliminating the interference of ions and inorganic constituents present in the samples.
\end{abstract}

\section{Introduction}

Aldehydes are a group of chemical compounds of the utmost importance in food and environmental science [1,2]. In alcoholic beverages, for example, aldehydes are commonly formed during the fermentation process. Due to the addition of flavors such as nut, fat, fruit or grass to the final product, their presence can have an important role on the flavor characteristics of these beverages. But, as aldehydes can greatly improve food quality, they can also generate unpleasant flavors, product deterioration and even cause health hazards [1,3-7]. Endogenous aldehydes are generated during oxidative stress and are associated with many pathogenic processes [8]. Not surprisingly, there are many analytical methodologies reported in literature based in a separation by gas-chromatography (GC) [8], liquid chromatography (LC) [3,9-12], and capillary electrophoresis (CE) for low molecular weight aldehydes on various matrices [2,13-17].

Derivatization procedures are a clever way to improve the susceptibility of analytes to be detected and quantified by many analytical instruments. It consists on the reaction between the aimed analytes with a derivatizing reagent producing derivates. Particularly, in chromatographic techniques, derivatization not only may lead to detectable compounds but can also improve their resolution and their symmetry;

\footnotetext{
* Correspondence to: Universidade Federal de São Carlos -UFSCAR, Departamento de Física, Química e Matemática, Rodovia João Leme dos Santos, Km 110, SP 264, CEP 18052-780 Sorocaba, SP, Brazil.

E-mail address: ealves@ufscar.br (E.A. Pereira).

1 These authors contributed equally for this work.
} 
derivates can be more stable, both chemically and thermally, thus a suitable analyte separation can be greatly improved [2,3,18-24]. One example of this is the group of compounds called hydrazines, that are a well-known group of derivatization agents for the detection and determination of carbonyl compounds in various samples [25]. There are other derivatizing agents for aldehydes in literature [24,26,27], including 2-aminoethanethiol, 2-diphenylacetyl-1,3-indandione-1-hydrazone, cyclohexane-1,3-dione, dansylhydrazine, 2,4-dinitrophenylhydrazine (DNPH) [3,28-30], 3-methylbenzothiazolin-2-one hydrazone (MBTH) [31], 4-(2-((4-bromophenethyl)dimethylammonio) ethoxy)benzenaminium dibromide (4-APEBA) [32], 2,4,6-trichlorophenylhydrazine [38], O-2,3,4,5,6-(pentafluorobenzyl) hydroxylamine hydrochloride (PFBO) [8,33], and benzoylhydrazine [2], all with their inherent advantages and disadvantages. As an example, DNPH, that is perhaps the most popular reagent for carbonyl compounds, also presents some disadvantages: large amount of impurities are found in the reagent, which may require additional purification steps prior to its use; furthermore, interferences with ozone and nitrogen dioxide $[34,35]$ have been reported, as well as low solubility in water and limited applicability in CE [36]. To overcome this limited applicability to $\mathrm{CE}$, the use of one other hydrazine, 4-hydrazinobenzoic acid (HBA) as a derivatizing agent for aldehydes is suggested. It was initially developed for the CE analysis of aldehydes present in air samples [13]. Considering the great potential of HBA, it was intended to apply it to more complex samples and observe if it was functional with LC. The derivatizing reaction is schematized in Fig. 1, the terminal primary amine in HBA reacts with the carbonyl group forming an imide.

Food and biological samples are very complex matrices with many different compounds present. A sample preparation step seems ideal not only to prolong the life span of the chromatographic columns and detectors but also to actually make a suitable detection possible [19]. In this work, gas-diffusion microextraction (GDME) was applied, a technique that merges microextration with gas-diffusion (hence ideal for volatile and semi-volatile compounds [37]) that is fully enhanced when a derivatizing reagent is used accordingly [38-40]. The GDME extraction device consists of a small hollow PTFE cylinder with a membrane at its bottom. Membrane type and characteristics can be adjusted according to the specific conditions in order to increase selectivity and sensitivity. Although GDME had been used before for aldehydes $[38,41,42]$, it has never been associated with HBA and never before associated with CE (although indeed other gas-diffusion techniques, particularly in flow systems, have been associated with CE [43-45]). When compared with other separation methods, like HPLC, CE has the advantages of a shorter time of analysis and lower sample consumption [46]. On the other hand, it has limited sensitivity and, when used with samples like beverages, can have the interference of ions and inorganic constituents [46]. These two issues can be solved using GDME, since not only it is possible to obtain enrichment factors ('pre-concentration') when applying derivatization but also only volatile and semi-volatile compounds are extracted ('clean-up').

\section{Materials and methods}

\subsection{Chemicals and samples}

All reagents were of analytical grade and, except when mentioned otherwise, were used without further purification. All aqueous solutions were prepared using ultrapure water with resistivity not lower than $18.2 \mathrm{M} \Omega \mathrm{cm}$ at $298 \mathrm{~K}$ (Direct-Q $3 \mathrm{UV}$, Millipore, Bedford, USA). Formaldehyde (For, methanal), acetaldehyde (Ace, ethanal), propionaldehyde (Pro, propanal), furfural (Fur, furan-2-carbaldehyde), acrolein (Acr, propenal), benzaldehyde (Ben), butyraldehyde (But, butanal), sodium dodecyl sulfate (SDS), sodium tetraborate (STB) and 4-hydrazinobenzoic acid (HBA) were obtained from Sigma-Aldrich (St. Louis, USA). Methanol, acetonitrile and hydrochloric acid were obtained from Merck (Darmstadt, Germany).

Stock standard solutions $\left(1000 \mathrm{mg} \mathrm{L}^{-1}\right)$ of each aldehyde were prepared in methanol, except For which was prepared in water. Daily work standard solutions $\left(100 \mathrm{mg} \mathrm{L}^{-1}\right)$ of each aldehyde were prepared by dilution of the stock solutions in methanol/water (1:1 in v/v). For the CE-DAD experiments, the stock derivatizing solution, $10 \mathrm{~mL}$ of HBA, concentration of $1000 \mathrm{mg} \mathrm{L}^{-1}$, was prepared daily in methanol/water (1:1 in $\mathrm{v} / \mathrm{v})$. This solution was protected from light. Working HBA solutions were prepared by diluting the stock solution in methanol/water (1:1 in $\mathrm{v} / \mathrm{v})$. For the HPLC-UV experiments, the stock derivatization solution, $10 \mathrm{~mL}$ of $\mathrm{HBA}$, concentration $2500 \mathrm{mg} \mathrm{L}^{-1}$, was daily prepared in $\mathrm{HCl} 0.1 \mathrm{~mol} \mathrm{~L}^{-1}$. This solution was kept in the dark, protected from light.

Samples (wine, cachaça and the other liquors) were purchased in local supermarkets.

\subsection{HPLC-UV}

The HPLC system (Thermo Electron Corp., USA) was composed of a low-pressure gradient quaternary pump with an autosampler (200-vial capacity sample) and a DAD detector (Finnigan Surveyor Plus). Chromatographic separations of the aldehydes-HBA derivatives were performed with a Phenomenex Gemini $\mathrm{C}_{18}(250 \times 4.60 \mathrm{~mm}, 5 \mu \mathrm{m}$ of particle size), the eluents and the gradient profile were optimized. Initial conditions consisted of acetonitrile (27\%) and formic acid, $0.1 \%$, in water $(73 \%)(\mathrm{v} / \mathrm{v})$; the gradient began with $27 \%$ of acetonitrile and increased to $43 \%$ in the following $25 \mathrm{~min}$; an increase to $51 \%$ in the next $7 \mathrm{~min}$ was performed, then returned to the initial conditions in $7 \mathrm{~min}$; an additional $5 \mathrm{~min}$ step was used for conditioning, before the next injection. The flow rate was $1.0 \mathrm{~mL} \mathrm{~min}^{-1}$, the injection volume was $20 \mu \mathrm{L}$, and the UV detection was performed at $320 \mathrm{~nm}$. All separations were made at room temperature (approximately $20^{\circ} \mathrm{C}$ ).

\subsection{CE-DAD}

CE was performed using a capillary electrophoresis system, model G7100A from Agilent Technologies (Palo Alto, USA). Separations were performed using a fused silica capillary (PolymicroTechnologies, Phoenix, USA) $58 \mathrm{~cm}$ of total length, $50 \mathrm{~cm}$ of effective length, $75 \mu \mathrm{m}$ i.d. x $375 \mu \mathrm{m}$ o.d., equipped with a diode array detector set at $290 \mathrm{~nm}$ and $320 \mathrm{~nm}$, the temperature control device was set at $27^{\circ} \mathrm{C}$. The samples were injected using hydrodynamic mode (25 mBar) during $10 \mathrm{~s}$. The instrument was operated under positive polarity at $+25 \mathrm{kV}$. Every day, before the first analysis, the capillary was conditioned by flushing with sodium hydroxide, $1 \mathrm{~mol} \mathrm{~L}^{-1}$ solution, during $5 \mathrm{~min}$, followed by a $5 \mathrm{~min}$ flush of purified water and $20 \mathrm{~min}$ flush of running electrolyte. In between samples injections, the capillary was rinsed by a $3 \mathrm{~min}$ flush with electrolyte solution (sodium tetraborate, $40 \mathrm{mmol} \mathrm{L}^{-1}$, $85 \%$, and acetonitrile, $15 \%$ ), which was prepared daily.

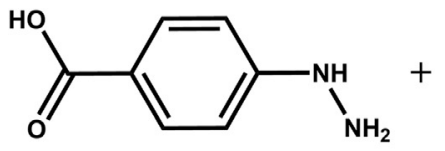

HBA
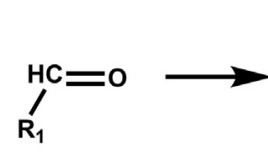

aldehyde

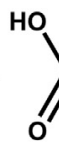

${ }_{0}^{\text {HO }}$
Fig. 1. Scheme of the derivatizing reaction, reaction between HBA and the different aldehydes forming an imine and a water molecule.

\section{-}

$\mathrm{H}_{2} \mathrm{O}$

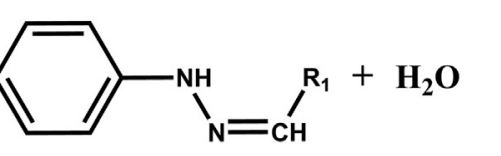

HBA-imine 


\section{4. $L C-M S$}

The separation in the LC-MS application was performed with a Phenomenex Gemini $\mathrm{C}_{18}$ column $(150 \times 4.6 \mathrm{~mm}, 3 \mu \mathrm{m}$ of particle size $)$ and a guard column with the same characteristics was used at room temperature, with a flow rate of $0.5 \mathrm{~mL} \mathrm{~min}^{-1}$ with an injection volume of $25 \mu \mathrm{L}$. The gradient and eluents used are shown in Table S1 in the Supporting information. A quadrupole ion-trap mass spectrometer (Finnigan LCQ Deca XP Plus) equipped with an electrospray ionization (ESI) source in the positive ion mode was used under the following conditions: capillary temperature, $325^{\circ} \mathrm{C}$; source voltage, $5.0 \mathrm{kV}$; capillary voltage, $3.0 \mathrm{~V}$; sheath gas $\left(\mathrm{N}_{2}\right)$ flow at 60 arbitrary units and auxiliary gas $\left(\mathrm{N}_{2}\right)$ flow at 22 arbitrary units. The mass detection was performed in the range $m / z 0-1000$. Xcalibur software version 1.4 (Thermo Electron Corp.) was used for data acquisition and processing.

\subsection{Derivatization and extraction procedure}

The initial studies of the derivatizing reaction were performed without any extraction (direct reaction). For the HPLC-UV analysis: $125 \mu \mathrm{L}$ of each working aldehyde standard solution were placed in a $5 \mathrm{~mL}$ volumetric flask and the volume was completed with HBA (312.5 $\mathrm{mg} \mathrm{L}^{-1}$ ), the mixed solution was allowed to react at room temperature, protected from the light for about $60 \mathrm{~min}$. For the CE-DAD analysis: $50 \mu \mathrm{L}$ of each working aldehyde standard solution were placed in a $5 \mathrm{~mL}$ volumetric flask and the volume was completed with HBA (300 $\mathrm{mg} \mathrm{L}^{-1}$ ), the mixed solution was allowed to react at room temperature protected from the light for about $60 \mathrm{~min}$.

Extraction was performed with a system of GDME [3,30,39] with appropriate minor modifications. Concerning the extraction conditions: a) HPLC-UV: $10 \mathrm{~mL}$ of the standard solution or sample (donor solution) were placed in the thermostatized flask; $500 \mu \mathrm{L}$ of HBA $\left(312.5 \mathrm{mg} \mathrm{L}^{-1}\right.$ ) was used as the acceptor solution, the time of extraction was $15 \mathrm{~min}$; b) CE-DAD: $15 \mathrm{~mL}$ of the standard solution or sample (donor solution) were placed in the thermostatized flask; $500 \mu \mathrm{L}$ of HBA $\left(300 \mathrm{mg} \mathrm{L}^{-1}\right)$ was used as the acceptor solution, the time of extraction was $20 \mathrm{~min}$. In both cases: the membrane used was PTFE with $0.5 \mu \mathrm{m}$ pore size (Mitex, Millipore), and the temperature was maintained at $50^{\circ} \mathrm{C}$ using a water bath, the extracts were left to react protected from light for about $40 \mathrm{~min}$.

\section{Results and discussion}

\subsection{Optimization of the separation conditions}

Initial conditions for the HPLC separation of aldehydes-HBA derivatives were based in the literature which described the analysis of HBA pharmaceutical formulations [47]. Several gradient programs were evaluated. Fig. S1 in the Supporting information presents the separation of HBA-aldehydes with an initial gradient tested. There were some problems separating HBA-Pro and HBA-Acr that could be solved with a slower increase in the acetonitrile percentage. The optimized separation of HBA derivatives using the final gradient profile is shown in Fig. 2.

According to literature [37] different parameters such as the acceptor solution's volume, whether the GDME device is immersed or suspended in the headspace, temperature and time of extraction, among others, can affect the extraction's efficiency. The acceptor solution's volume (derivatization solution, HBA $200 \mathrm{mg} \mathrm{L}^{-1}$ ) was studied on the extraction efficiency simultaneously comparing both immersion and headspace modes (Fig. 3). The volume of the HBA solution placed inside of the extracting probe varied in the range from 300 to $1000 \mu \mathrm{L}$ (experiments HM 300, HM 500, HM 700 and HM 1000 in Fig. 3), keeping the time and temperature of extraction constant (20 min and $50{ }^{\circ} \mathrm{C}$, respectively). With increasing HBA solution volume, a decrease in the analytical signal for all aldehydes was observed. A volume of $500 \mu \mathrm{L}$ was selected for the following experiments for practical aspects,

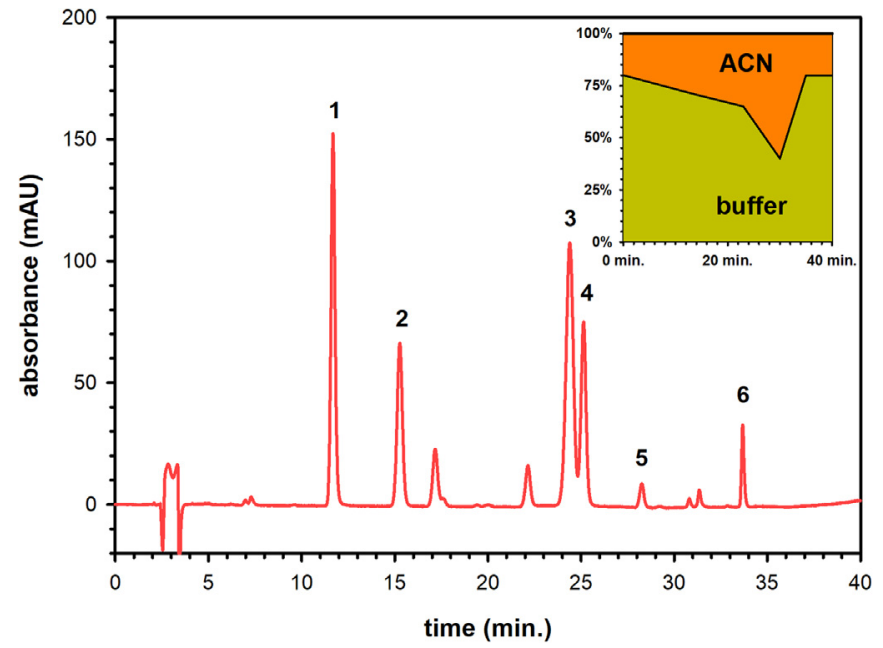

Fig. 2. Chromatograms of the optimized separation of the aldehydes-HBA derivates. Inlay: schematics of the gradient used in each case. All aldehydes had concentration of $10 \mathrm{mg} \mathrm{L}^{-1}$, with the exception of For that was $2.5 \mathrm{mg} \mathrm{L}^{-1}$. Peaks identification: 1 - HBA-For (4-(2-methylenehydrazineyl)benzoic acid), 2 HBA-Ace (4-(2-ethylidenehydrazineyl)benzoic acid), 3 - HBA-Pro (4-(2-propylidenehydrazineyl)benzoic acid), 4 - HBA-Acr (4-(2-allylidenehydrazineyl)benzoic acid), 5 - HBA-Fur (4-(2-(furan-2-ylmethylene)hydrazineyl)benzoic acid), and 6 - Hba-Ben (4-(2-benzylidenehydrazineyl)benzoic acid). Gradient elution: starting with 80:20 (\% of buffer of phosphoric acid, $20 \mathrm{mmol} \mathrm{L}^{-1}, \mathrm{pH} \mathrm{2.5}$; and $\%$ of acetonitrile), gradually changing to $70: 30$ during $15 \mathrm{~min}$, then gradually changing to $65: 35$ during $8 \mathrm{~min}$, another gradual change to 40:60 during $7 \mathrm{~min}$, stable gradient for $10 \mathrm{~min}$, gradually changing to 80:20 during $5 \mathrm{~min}$, finishing with a stable gradient for $5 \mathrm{~min}$.

the handling of the extract was experimentally simpler. This volume was compared in the immersion and headspace mode experiments (HM 500 and IM 500 in Fig. 3), the immersion presented an increase on the analytical signal, mainly for For, Fur and Ben, probably due to lower volatility than the other aldehydes.

The effect of temperature on extraction was evaluated in the range from $40^{\circ}$ to $60^{\circ} \mathrm{C}$ (Fig. 4 - A). The For analytical signal increased with increasing temperature, however, no significant variations on peak area were observed for Ace, Pro, Fur and Ben, though it was observed a decrease in Acr. Another parameter evaluated was the extraction time, it was tested in a range from 10 to $30 \mathrm{~min}$ (Fig. 4 - B). It was observed that the analytical signal increases with increasing extraction time for Ace, Pro and Acr, however, a loss of signal was observed for For, Fur and Ben for a time larger than $30 \mathrm{~min}$. Consequently, the optimized temperature and time were set to $50{ }^{\circ} \mathrm{C}$ and $20 \mathrm{~min}$, respectively.

The extraction using the immersion mode was evaluated by comparing the extraction system with and without stirring (Fig. S2 in the Supporting information). The stirring of the sample caused a small increase in the analytical signal for Ace, Pro and Acr, no significant variations for Fur and Ben and slight decrease to For, probably due to competition for the derivatizing agent.

Since the temperature and time of extraction had been evaluated and optimized in HPLC-UV experiments, the same conditions were used for the CE-DAD analysis. Initial results with CE showed that poor resolution occurred between peaks of aldehydes evaluated with electrolyte containing only STB (Fig. 5 - A). The effect of addition of methanol and acetonitrile on the separation was evaluated using each organic solvent in the range of 5-15\%, with constant electrolyte concentration, injection, applied voltage and temperature $\left(40 \mathrm{mmol} \mathrm{L}^{-1} \mathrm{STB} \mathrm{pH} 9.45\right.$, $10 \mathrm{~s} \mathrm{x} 25 \mathrm{mBar},+25 \mathrm{kV}$ and $27^{\circ} \mathrm{C}$ ). It was found that $15 \%$ acetonitrile improved resolution of all peaks (Fig. $5-\mathrm{B}$ and C). When studying the influence of the reaction medium solvent, it was observed that methanol showed better performance (improved signal analytical for Ace, Pro, Fur and Ben) than acetonitrile. Studies with binary mixtures of 

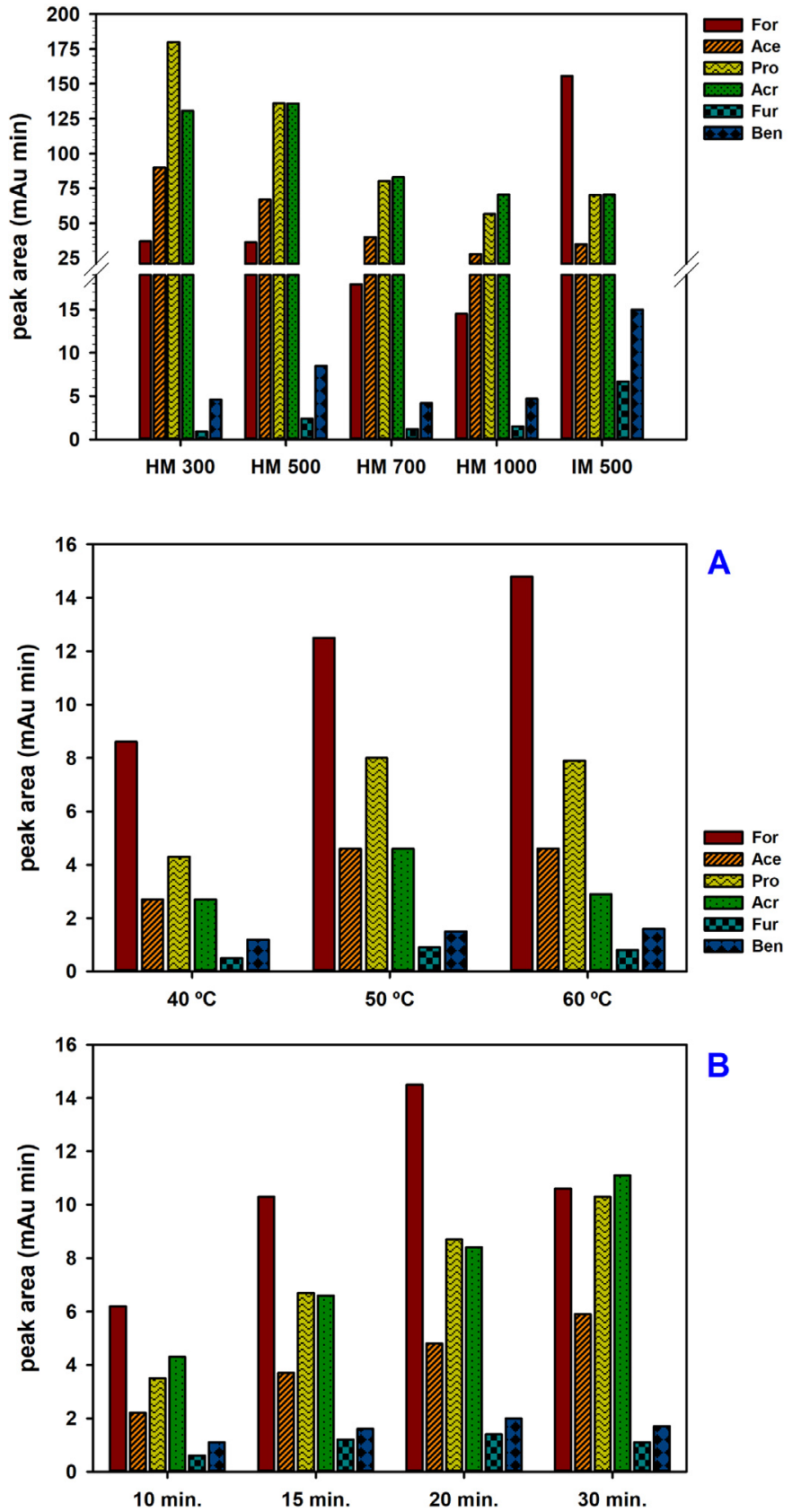

B

Fig. 4. Extraction optimization studies, in both a mixture of aldehydes with concentrations of $2.5 \mathrm{mg} \mathrm{L}^{-1}$ of each aldehyde, immersion mode, HBA volume of $500 \mu \mathrm{L}$, without shaking: (A) Effect of temperature on extraction procedure, extraction time of $20 \mathrm{~min}$; (B) Effect of time in the extraction, temperature of $50{ }^{\circ} \mathrm{C}$.

$1: 1 \mathrm{v} / \mathrm{v}$ purified water:methanol and $1: 1 \mathrm{v} / \mathrm{v}$ water:acetonitrile with different times of reaction can be found in the Supporting Information (Fig. S3).

The derivatization reaction between HBA and the aldehydes was conducted under three $\mathrm{pH}$ values conditions: 2.5, 5.1 and 7.0. The $\mathrm{pH}$ of the derivatization solution was adjusted with hydrochloric acid and sodium hydroxide. The $\mathrm{pH}$ value of 5.1 was not adjusted (dissolution of reagent and binary mixture). Derivatization time was about $60 \mathrm{~min}$ [13]. When the $\mathrm{pH}$ was increased from 5.1 to 7.0, no further improvements in the analytical signal for Ace and Pro were observed, however it was observed a decrease in the analytical signal for For, Fur and Ben (Fig. 6). The derivatization reagent without any $\mathrm{pH}$ adjustment was selected as the optimum condition. This result is explained by the

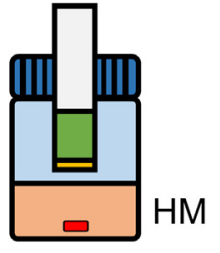

Fig. 3. Extraction optimization concerning the acceptor solution's volume, and the immersed mode (IM) vs. headspace mode (HM). Extraction conditions: temperature of $50{ }^{\circ} \mathrm{C}$, extraction time of $20 \mathrm{~min}$, aldehydes concentrations of $10 \mathrm{mg} \mathrm{L}^{-1}$. (HM 300) Headspace mode, HBA volume of $300 \mu \mathrm{L}$; (HM 500) Headspace mode, HBA volume of $500 \mu \mathrm{L}$; (HM 700) Headspace mode, HBA volume of $700 \mu \mathrm{L}$; (HM 1000) Headspace mode, HBA volume of $1000 \mu \mathrm{L}$; (IM 500) Immersion mode, HBA volume of $500 \mu \mathrm{L}$. On the right side there is a scheme depicting what are the headspace and immersion modes.

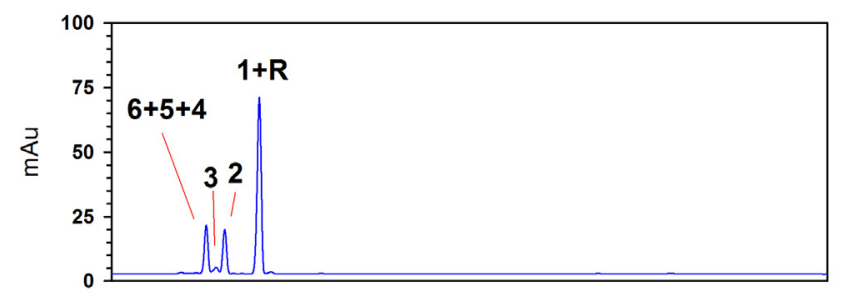

A
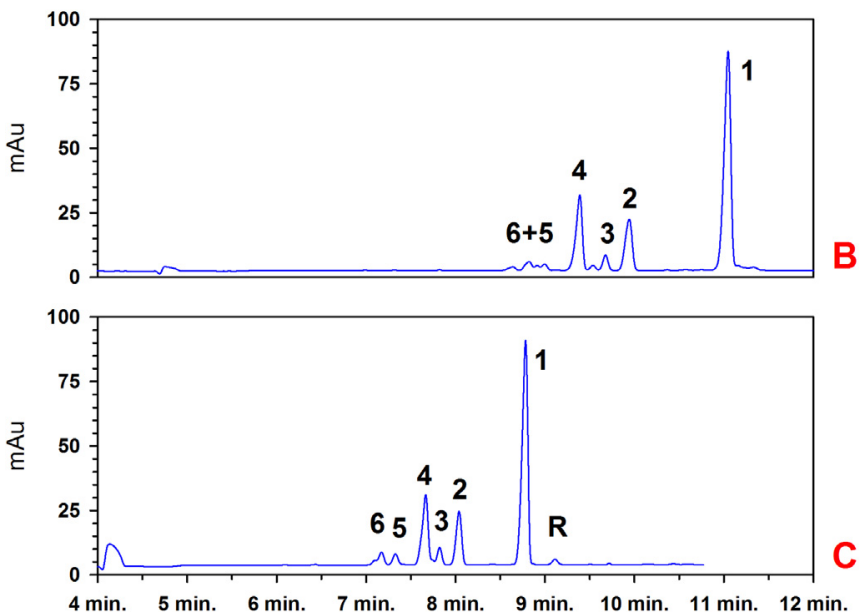

Fig. 5. Electropherograms of the separation of the different aldehyde-HBA derivatives, at a concentration of $10 \mathrm{mg} \mathrm{L}^{-1}$, injection of $10 \mathrm{~s}$ at $25 \mathrm{mBar}$, potential of $+25 \mathrm{kV}$, temperature of $27^{\circ} \mathrm{C}$, wavelength of $290 \mathrm{~nm}$. Peak identification: R - excess of HBA, 1 - HBA-For, 2 - HBA-Ace, 3 - HBA-Acr, 4 - HBAPro, 5 - HBA-Fur and 6 - HBA-Ben. (A) electrolyte: $40 \mathrm{mmol} \mathrm{L}^{-1} \mathrm{STB}$, $\mathrm{pH} 9.45$; (B) $40 \mathrm{mmol} \mathrm{L}^{-1} \mathrm{STB}, \mathrm{pH} 9.45+15 \%$ methanol; (C) $40 \mathrm{mmol} \mathrm{L}^{-1} \mathrm{STB}, \mathrm{pH}$ $9.45+15 \%$ acetonitrile.

reaction mechanism schematized in Fig. 6. The reaction between a primary amine and an aldehyde to form an imine follows this alkylimino-de-oxo-bisubstitution mechanism: 1) nucleophilic attack from the amine's nitrogen to the aldehyde's carbon; 2) proton transfer originating an hemianal (also known as carbinolamine); 3) protonation of the hydroxyl (in this case the Lewis' acid is an hydronium ion); 4) elimination of water; 5) deprotonation. Step 1 and step 4 are the rate-determining steps depending on the $\mathrm{pH}$ : a) for a $\mathrm{pH}$ below 4, step 1 limits the reaction because too much acid will protonate the unprotected amine (i.e. rate-determining addition); b) for a $\mathrm{pH}$ higher than 6 , step 4 is limited because the elimination of water is not favored (i.e. rate-determining dehydration) [48]. As a result, theoretically the optimum $\mathrm{pH}$ is around 5 [48], this is precisely what was obtained experimentally. Imines are in general rather unstable, one of the exceptions are hydrazones, the electronegativity of the extra nitrogen participates in the delocalization of the imine's double bond, delocalization decreases the small positive 

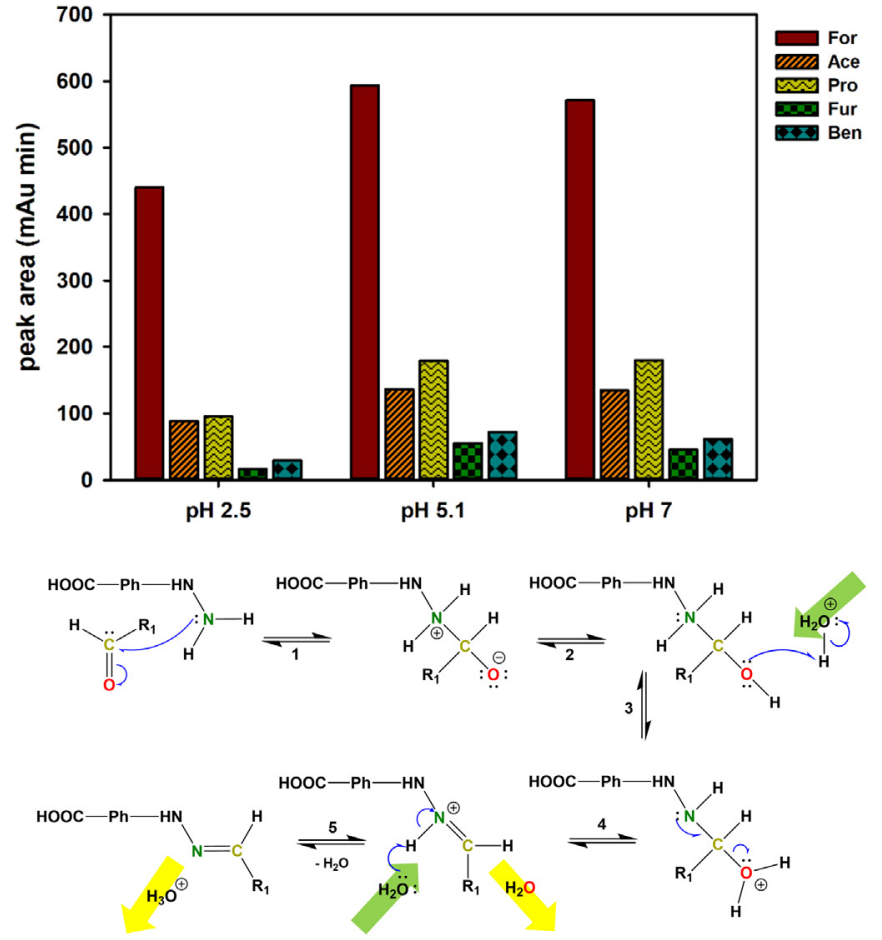

Fig. 6. Effect of the $\mathrm{pH}$ in the derivatization reaction, measurements were performed with CE-DAD (injection of $10 \mathrm{~s}$ at $25 \mathrm{mBar}$, potential of $+25 \mathrm{kV}$, temperature of $27^{\circ} \mathrm{C}$, wavelength of $290 \mathrm{~nm}$, electrolyte: $40 \mathrm{mmol} \mathrm{L}^{-1} \mathrm{STB}, \mathrm{pH}$ $9.45+15 \%$ acetonitrile), the different aldehyde-HBA derivatives were at the concentration of $10 \mathrm{mg} \mathrm{L}^{-1}$. Below the reaction mechanism: 1) nucleophilic attack; 2) proton transfer; 3) protonation of the hydroxyl; 4) elimination of water; 5) deprotonation.

charge on the imine's carbon making it less susceptible to nucleophilic attack [48].

In order to provide an extra dimension of information to the already rich data of HPLC-UV and CE-DAD, HPLC-DAD-MS/MS studies were also performed. The combination between the retention time and the MS spectral information of the several aldehyde derivatives present from standards enabled highly reliable identification and confirmation of the compounds. The most relevant data is summarized in Fig. 7. It seems that all derivates were mostly fragmented in the carboxylic group releasing a water molecule, thus the most intense fragment is $18 \mathrm{Da}$ short from the root compound. The N-N covalent bond also seems to be a 'weak' interaction easily broken.
Table 1

Analytical parameters. Values of the slope and intercept are expressed along with the confidence interval at the significance level of 0.05. For GDME-CE$\mathrm{DAD} \mathrm{n}=5$ and for GDME-HPLC-UV $\mathrm{n}=5$. All measurements were performed in duplicate or triplicate.

\begin{tabular}{|c|c|c|c|}
\hline & & GDME-HPLC-UV & GDME-CE-DAD \\
\hline \multirow[t]{7}{*}{ LOD $\left(\mathrm{mg} \mathrm{L}^{-1}\right)$} & Ace & 0.15 & 0.45 \\
\hline & Pro & 0.17 & 0.35 \\
\hline & Acr & 0.08 & - \\
\hline & Fur & 0.21 & 0.35 \\
\hline & Ben & 0.15 & 0.39 \\
\hline & For & 0.005 & 0.36 \\
\hline & But & 0.07 & - \\
\hline \multirow[t]{7}{*}{$\operatorname{LOQ}\left(\mathrm{mg} \mathrm{L}^{-1}\right)$} & Ace & 0.50 & 1.49 \\
\hline & Pro & 0.57 & 1.18 \\
\hline & Acr & 0.25 & - \\
\hline & Fur & 0.69 & 1.16 \\
\hline & Ben & 0.50 & 1.32 \\
\hline & For & 0.017 & 1.21 \\
\hline & But & 0.23 & - \\
\hline \multirow[t]{7}{*}{$\mathbf{r}^{2}$} & Ace & 0.996 & 0.999 \\
\hline & Pro & 0.995 & 0.999 \\
\hline & Acr & 0.999 & - \\
\hline & Fur & 0.993 & 0.999 \\
\hline & Ben & 0.996 & 0.999 \\
\hline & For & 0.999 & 0.999 \\
\hline & But & 0.997 & - \\
\hline
\end{tabular}

\subsection{Analytical parameters and sample analysis}

The method performance parameters were obtained from several calibration curves, for both GDME-HPLC-UV and GDME-CE-DAD, using the analytical procedures previously described, results are summarized in Table 1. The obtained results showed that linearity for all aldehydes was suitable with all coefficients of determination $\left(\mathrm{r}^{2}\right)$ above 0.99 . The linear ranges using GDME-CE-DAD were up to $15 \mathrm{mg} \mathrm{L}^{-1}$ for all compounds, and using GDME-HPLC-UV were up to $10 \mathrm{mg} \mathrm{L}^{-1}$ for all compounds. The limit of detection (LOD) and limit of quantification (LOQ) were calculated as three and ten times the standard deviation of the intercept divided by the slope, respectively, and were all below $0.5 \mathrm{mg} \mathrm{L}^{-1}$ (Table 1). Apart from other aldehydes or ketones, it is not expected that other compounds can be simultaneously extracted and react with HBA, thus no selectivity tests were performed.

The practical applicability of the developed methodologies was tested in the analysis of For and Ace using spiking techniques in different kind of alcoholic beverages. The obtained results are shown in Table 2 (Fig. S4 in the Supporting information shows an example of a chromatogram obtained in the analysis one of the samples by GDMEHPLC-UV, and Fig. S5 in the Supporting information shows an example of an electropherogram obtained in the analysis one of the samples by

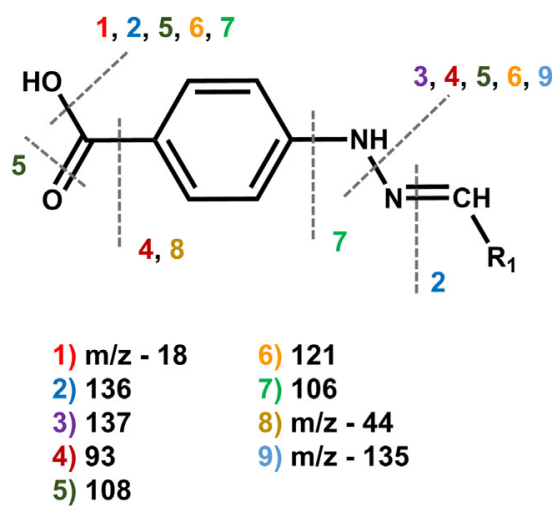

\begin{tabular}{|c|c|c|c|c|}
\hline derivate & MW / Da & $\mathrm{m} / \mathbf{z}$ & main fragment & other fragments \\
\hline HBA-For & 164 & 165 & 147 & $\begin{array}{c}136,93,119,133,146 \\
137,120,108,92,94\end{array}$ \\
\hline HBA-Ace & 178 & 179 & 161 & $\begin{array}{c}135,136,118,134,93 \\
94,133,163,137\end{array}$ \\
\hline HBA-Pro & 192 & 193 & 175 & $\begin{array}{c}132,149,136,176,93 \\
94,95,119,107\end{array}$ \\
\hline HBA-Acr & 190 & 191 & 173 & $\begin{array}{c}119,136,147,132,130 \\
146,148,145,137\end{array}$ \\
\hline HBA-Fur & 230 & 231 & 213 & $\begin{array}{c}119,187,169,163,185 \\
96,93,203,207\end{array}$ \\
\hline HBA-But & 206 & 207 & 189 & $\begin{array}{c}146,163,190,136,165 \\
94,172,121,119,104\end{array}$ \\
\hline HBA-Ben & 240 & 241 & 223 & $\begin{array}{c}197,119,195,136,119 \\
106,93\end{array}$ \\
\hline
\end{tabular}

Fig. 7. Overview of the MS fragmentation. Main fragments are listed for each aldehyde-HBA derivative, other fragments are listed in order of magnitude. 
Table 2

Determination of For and Ace in several alcoholic beverages $(n=3)$ by the two diffetent analytical methodologies developed.

\begin{tabular}{lcc}
\hline Sample & [For] $\left(\mathrm{mg} \mathrm{L}^{-1}\right)$ & [Ace] / $\left(\mathrm{mg} \mathrm{L}^{-1}\right)$ \\
\hline GDME-HPLC-UV & & \\
'Ginja' liquor & $<0.017$ & $86 \pm 6$ \\
'Beirão' liquor & $<0.017$ & $22 \pm 2$ \\
Port wine & $0.13 \pm 0.09$ & $88 \pm 2$ \\
white wine A & $<0.017$ & $11.0 \pm 0.6$ \\
red wine A & $0.75 \pm 0.04$ & $8.1 \pm 0.2$ \\
GDME-CE-DAD & $<1.21$ & \\
white wine B & $1.58 \pm 0.08$ & $5.2 \pm 0.1$ \\
red wine B & $<1.21$ & $5.2 \pm 0.1$ \\
white wine C & $<1.21$ & $<1.49$ \\
red wine C & $6.4 \pm 0.2$ & $<1.49$ \\
cachaça & & $56.8 \pm 0.9$ \\
\hline
\end{tabular}

GDME-CE-DAD). No pre-treatment of the samples was applied and the obtained values were in accordance with the ones commonly found in similar products [30]. It was chosen to analyze only these two compounds since the concentration of other aldehydes was expected to be too low and might require longer extraction times.

\section{Conclusions}

A new derivatizing agent was successfully applied in a novel methodology aiming the determination of low molecular weight aldehydes. The derivatization with HBA was simple, quick, and only one derivative is formed from each different aldehyde. The formed derivates were analyzed by HPLC-UV and CE-DAD, being further studied by LC-MS. GDME is ideal to be used in complex samples since it allows simple and simultaneous clean-up and pre-concentration steps. The developed methodologies showed satisfactory results concerning linearity and precision.

\section{Acknowledgements}

TAD wishes to acknowledge to Programa de Pós-Graduação em Biotecnologia e Monitoralmento (PPGBMA) UFSCar, Campus Sorocaba and Coordenação de Aperfeiçoamento de Pessoal de Nível Superior (CAPES) of Brazil for the fellowship. EAP also would like to acknowledge Fundação de Amparo à Pesquisa do Estado de São Paulo for financial support (FAPESP 11/23286-1). This work received financial support from Fundação para a Ciência e a Tecnologia/Ministro da Ciência, Tecnologia e Ensino Superior (FCT/MCTES) through national funds and co-financed by (CAPES/FCT 99999.008406/2014-06) and Fundo Europeu de Desenvolvimento Regional (FEDER), under the Partnership Agreement PT2020 through projects UID/QUI/50006/ 2013 and POCI/01/0145/FEDER/007265, which includes a studentship to PFB and RMR. LMG further wishes to acknowledge FCT (SFRH/ BPD/76544/2011 and FCT/13277/4/8/2015/S)

\section{Conflicts of interest}

There are no conflicts of interest to declare.

\section{Appendix A. Supporting information}

Supplementary data associated with this article can be found in the online version at http://dx.doi.org/10.1016/j.talanta.2018.04.091.

\section{References}

1] J. Schultheiss, D. Jensen, R. Galensa, Determination of aldehydes in food by highperformance liquid chromatography with biosensor coupling and micromembrane suppressors, J. Chromatogr. A 880 (2000) 233-242, http://dx.doi.org/10.1016/
S0021-9673(99)01086-9.

[2] T.A. Donegatti, L.M. Gonçalves, E.A. Pereira, Derivatizing assay for the determination of aldehydes using micellar electrokinetic chromatography, Electrophoresis 38 (2017) 1068-1074, http://dx.doi.org/10.1002/elps.201600483.

[3] L.M. Gonçalves, P.J. Magalhães, I.M. Valente, J.G. Pacheco, P. Dostálek, D. Sýkora, J.A. Rodrigues, A.A. Barros, Analysis of aldehydes in beer by gas-diffusion microextraction: characterization by high-performance liquid chromatography-diodearray detection-atmospheric pressure chemical ionization-mass spectrometry, J. Chromatogr. A 1217 (2010) 3717-3722, http://dx.doi.org/10.1016/j.chroma. 2010.04.002.

[4] S. Wang, X. Cui, G. Fang, Rapid determination of formaldehyde and sulfur dioxide in food products and Chinese herbals, Food Chem. 103 (2007) 1487-1493, http:// dx.doi.org/10.1016/j.foodchem.2006.09.023.

[5] H.S. Jeong, H. Chung, S.H. Song, C. Il Kim, J.G. Lee, Y.S. Kim, Validation and determination of the contents of acetaldehyde and formaldehyde in foods, Toxicol. Res. 31 (2015) 273-278, http://dx.doi.org/10.5487/TR.2015.31.3.273.

[6] W. Wang, G. Li, Z. Ji, N. Hu, J. You, A novel method for trace aldehyde determination in foodstuffs based on fluorescence labeling by HPLC with fluorescence detection and mass spectrometric identification, Food Anal. Methods 7 (2014) 1546-1556, http://dx.doi.org/10.1007/s12161-013-9787-1.

[7] J.B. Zhang, M.J. Li, W.L. Li, Q.C. Chu, J.N. Ye, A novel capillary electrophoretic method for determining aliphatic aldehydes in food samples using 2-thiobarbituric acid derivatization, Electrophoresis 32 (2011) 705-711, http://dx.doi.org/10. 1002/elps.201000533.

[8] M. Serrano, M. Gallego, M. Silva, Analysis of endogenous aldehydes in human urine by static headspace gas chromatography-mass spectrometry, J. Chromatogr. A 1437 (2016) 241-246, http://dx.doi.org/10.1016/j.chroma.2016.01.056.

[9] X. Xu, R. Su, X. Zhao, Z. Liu, D. Li, X. Li, H. Zhang, Z. Wang, Determination of formaldehyde in beverages using microwave-assisted derivatization and ionic liquid-based dispersive liquid-liquid microextraction followed by high-performance liquid chromatography, Talanta 85 (2011) 2632-2638, http://dx.doi.org/10.1016/ j.talanta.2011.08.037.

[10] P. Wahed, M.A. Razzaq, S. Dharmapuri, M. Corrales, Determination of formaldehyde in food and feed by an in-house validated HPLC method, Food Chem. 202 (2016) 476-483, http://dx.doi.org/10.1016/j.foodchem.2016.01.136.

[11] H. Wang, J. Ding, X. Du, X. Sun, L. Chen, Q. Zeng, Y. Xu, X. Zhang, Q. Zhao, L. Ding, Determination of formaldehyde in fruit juice based on magnetic strong cation-exchange resin modified with 2,4-dinitrophenylhydrazine, Food Chem. 131 (2012) 380-385, http://dx.doi.org/10.1016/j.foodchem.2011.08.056.

[12] H.-J. Kim, H.-S. Shin, Simple derivatization of aldehydes with D-cysteine and their determination in beverages by liquid chromatography-tandem mass spectrometry, Anal. Chim. Acta 702 (2011) 225-232, http://dx.doi.org/10.1016/j.aca.2011.07. 006.

[13] E.A. Pereira, M.O.O. Rezende, M.F.M. Tavares, Analysis of low molecular weigh aldehydes in air samples by capillary electrophoresis after derivatization with 4hydrazinobenzoic acid, J. Sep. Sci. 27 (2004) 28-32, http://dx.doi.org/10.1002/ jssc. 200301665.

[14] M.F.M. Tavares, A.V. Jager, C.L. Da Silva, E.P. Moraes, E.A. Pereira, E.C. De Lima, F.N. Fonseca, F.G. Tonin, G.A. Micke, M.R. Santos, M.A.L. De Oliveira, M.D.L.L. De Moraes, M.H. Van Kampen, N.M. Fujiya, Applications of capillary electrophoresis to the analysis of compounds of clinical, forensic, cosmetological, environmental, nutritional and pharmaceutical importance, J. Braz. Chem. Soc. 14 (2003) 281-290, http://dx.doi.org/10.1590/S0103-50532003000200016.

[15] E.A. Pereira, A.A. Cardoso, M.F.M. Tavares, Determination of low-aliphatic aldehydes indoors by micellar electrokinetic chromatography using sample dissolution manipulation for signal enhancement, Electrophoresis 24 (2003) 700-706, http:// dx.doi.org/10.1002/elps.200390084.

[16] E.A. Pereira, E. Carrilho, M.F.M. Tavares, Laser-induced fluorescence and UV detection of derivatized aldehydes in air samples using capillary electrophoresis, J. Chromatogr. A 979 (2002) 409-416, http://dx.doi.org/10.1016/S0021-9673(02) 01258-X.

[17] T. Acunha, C. Ibáñez, V. García-Cañas, C. Simó, A. Cifuentes, Recent advances in the application of capillary electromigration methods for food analysis and Foodomics, Electrophoresis 37 (2016) 111-141, http://dx.doi.org/10.1002/elps.201500291.

[18] J.-Y. Wang, X.-J. Wang, X. Hui, S.-H. Hua, H. Li, W.-Y. Gao, Determination of Diacetyl in Beer by a Precolumn Derivatization-HPLC-UV Method Using 4-(2,3Dimethyl-6-quinoxalinyl) - 1,2-benzenediamine as a Derivatizing Reagent, J. Agric. Food Chem. 65 (2017) 2635-2641, http://dx.doi.org/10.1021/acs.jafc.7b00990.

[19] L.M. Gonçalves, I.M. Valente, J.A. Rodrigues, Recent Advances in Membrane-Aided Extraction and Separation for Analytical Purposes, Sep. Purif. Rev. 46 (2017) 179-194, http://dx.doi.org/10.1080/15422119.2016.1235050.

[20] J.C.M. Waterval, H. Lingeman, A. Bult, W.J.M. Underberg, Derivatization trends in capillary electrophoresis, Electrophoresis 21 (2000) 4029-4045, http://dx.doi.org/ 10.1002/1522-2683(200012)21:18< 4029::AID-ELPS4029 > 3.0.CO;2-S.

[21] B.-L. Qi, P. Liu, Q.-Y. Wang, W.-J. Cai, B.-F. Yuan, Y.-Q. Feng, Derivatization for liquid chromatography-mass spectrometry, TrAC Trends Anal. Chem. 59 (2014) 121-132, http://dx.doi.org/10.1016/j.trac.2014.03.013.

[22] A.M. Carro, P. González, R.A. Lorenzo, Applications of derivatization reactions to trace organic compounds during sample preparation based on pressurized liquid extraction, J. Chromatogr. A 1296 (2013) 214-225, http://dx.doi.org/10.1016/j . chroma.2013.04.068.

[23] J.E. Szulejko, K.-H. Kim, Derivatization techniques for determination of carbonyls in air, TrAC Trends Anal. Chem. 64 (2015) 29-41, http://dx.doi.org/10.1016/j. trac.2014.08.010.

[24] Y.Z. Baghdady, K.A. Schug, Review of in situ derivatization techniques for enhanced bioanalysis using liquid chromatography with mass spectrometry, J. Sep. Sci. 39 
(2016) 102-114, http://dx.doi.org/10.1002/jssc.201501003.

[25] M. Vogel, A. Büldt, U. Karst, Hydrazine reagents as derivatizing agents in environmental analysis - a critical review, Fresenius J. Anal. Chem. 366 (2000) 781-791, http://dx.doi.org/10.1007/s002160051572.

[26] H. Nishikawa, T. Sakai, Derivatization and chromatographic determination of aldehydes in gaseous and air samples, J. Chromatogr. A 710 (1995) 159-165, http:// dx.doi.org/10.1016/0021-9673(94)01006-Z.

[27] M. Eggink, M. Wijtmans, R. Ekkebus, H. Lingeman, I.J.P. de Esch, J. Kool, W.M.A. Niessen, H. Irth, Development of a selective ESI-MS derivatization reagent: synthesis and optimization for the analysis of aldehydes in biological mixtures, Anal. Chem. 80 (2008) 9042-9051, http://dx.doi.org/10.1021/ac801429w.

[28] H.H. Jeleń, A. Dąbrowska, D. Klensporf, J. Nawrocki, E. Wąsowicz, Determination of C3-C10 aliphatic aldehydes using PFBHA derivatization and solid phase microextraction (SPME). application to the analysis of beer, Chem. Anal. 49 (2004) 869-880〈https://www.scopus.com/inward/record.uri?eid = 2-s2.0-13844264485 \&partnerID $=40 \& \mathrm{md} 5=29 \mathrm{~d} 505 \mathrm{bbc} 473 \mathrm{f} 6 \mathrm{~b} 7 \mathrm{cbf19} 4 \mathrm{~b} 414 \mathrm{f} 2 \mathrm{e} 84 \mathrm{~d}\rangle$.

[29] Y.-L. Lin, P.-Y. Wang, L.-L. Hsieh, K.-H. Ku, Y.-T. Yeh, C.-H. Wu, Determination of linear aliphatic aldehydes in heavy metal containing waters by high-performance liquid chromatography using 2,4-dinitrophenylhydrazine derivatization, J. Chromatogr. A 1216 (2009) 6377-6381, http://dx.doi.org/10.1016/j.chroma. 2009.07.018.

[30] M.P. Cruz, I.M. Valente, L.M. Gonçalves, J.A. Rodrigues, A.A. Barros, Application of gas-diffusion microextraction to the analysis of free and bound acetaldehyde in wines by HPLC-UV and characterization of the extracted compounds by MS/MS detection, Anal. Bioanal. Chem. 403 (2012) 1031-1037, http://dx.doi.org/10. 1007/s00216-011-5664-1.

[31] J. Ledauphin, D. Barillier, M. Beljean-Leymarie, Gas chromatographic quantification of aliphatic aldehydes in freshly distilled Calvados and Cognac using 3-methylbenzothiazolin-2-one hydrazone as derivative agent, J. Chromatogr. A 1115 (2006) 225-232, http://dx.doi.org/10.1016/j.chroma.2006.02.080.

[32] M. Eggink, M. Wijtmans, A. Kretschmer, J. Kool, H. Lingeman, I.J.P. de Esch, W.M.A. Niessen, H. Irth, Targeted LC-MS derivatization for aldehydes and carboxylic acids with a new derivatization agent 4-APEBA, Anal. Bioanal. Chem. 397 (2010) 665-675, http://dx.doi.org/10.1007/s00216-010-3575-1.

[33] J. Ma, R. Xiao, J. Li, J. Li, B. Shi, Y. Liang, W. Lu, L. Chen, Headspace solid-phase microextraction with on-fiber derivatization for the determination of aldehydes in algae by gas chromatography-mass spectrometry, J. Sep. Sci. 34 (2011) 1477-1483, http://dx.doi.org/10.1002/jssc.201000860.

[34] D.F. Smith, T.E. Kleindienst, E.E. Hudgens, Improved high-performance liquid chromatographic method for artifact-free measurements of aldehydes in the presence of ozone using 2,4-dinitrophenylhydrazine, J. Chromatogr. A 483 (1989) 431-436, http://dx.doi.org/10.1016/S0021-9673(01)93146-2.

[35] R.R. Arnts, S.B. Tejada, 2,4-Dinitrophenylhydrazine-coated silica gel cartridge method for determination of formaldehyde in air: identification of an ozone in terference, Environ. Sci. Technol. 23 (1989) 1428-1430, http://dx.doi.org/10. 1021/es00069a018.

[36] U. Karst, N. Binding, K. Cammann, U. Witting, Interferences of nitrogen dioxide in the determination of aldehydes and ketones by sampling on 2,4-dinitrophenylhydrazine-coated solid sorbent, Fresenius. J. Anal. Chem. 345 (1993) 48-52, http:// dx.doi.org/10.1007/BF00323325.

[37] C.M. Santos, I.M. Valente, L.M. Goncalves, J.A. Rodrigues, Chromatographic analysis of methylglyoxal and other [small alpha]-dicarbonyls using gas-diffusion microextraction, Analyst 138 (2013) 7233-7237, http://dx.doi.org/10.1039/ C3AN00766A.

[38] L.M. Gonçalves, P.J. Magalhães, I.M. Valente, J.G. Pacheco, P. Dostálek, D. Sýkora, J.A. Rodrigues, A.A. Barros, Analysis of aldehydes in beer by gas-diffusion microextraction: characterization by high-performance liquid chromatography-diodearray detection-atmospheric pressure chemical ionization-mass spectrometry, J. Chromatogr. A 1217 (2010) 3717-3722, http://dx.doi.org/10.1016/j.chroma. 2010.04.002.

[39] J.G. Pacheco, I.M. Valente, L.M. Gonçalves, J.A. Rodrigues, A.A. Barros, Gas-diffusion microextraction, J. Sep. Sci. 33 (2010) 3207-3212, http://dx.doi.org/10. 1002/jssc. 201000351.

[40] R.M. Ramos, L.M. Gonçalves, V. Vyskočil, J.A. Rodrigues, Voltammetric determination of trace amounts of diacetyl at a mercury meniscus modified silver solid amalgam electrode following gas-diffusion microextraction, Talanta 169 (2017) 203-208, http://dx.doi.org/10.1016/j.talanta.2017.03.077.

[41] P.F. Brandão, R.M. Ramos, I.M. Valente, P.J. Almeida, A.M. Carro, R.A. Lorenzo, J.A. Rodrigues, Gas-diffusion microextraction coupled with spectrophotometry for the determination of formaldehyde in cork agglomerates, Anal. Bioanal. Chem. 409 (2017) 2885-2892, http://dx.doi.org/10.1007/s00216-017-0233-x.

[42] P.F. Brandão, R.M. Ramos, P.J. Almeida, J.A. Rodrigues, Determination of carbonyl compounds in cork agglomerates by GDME-HPLC-UV: identification of the extracted compounds by HPLC-MS/MS, J. Agric. Food Chem. 65 (2017) 1037-1042, http://dx.doi.org/10.1021/acs.jafc.6b05370.

[43] P. Kuban, On-line coupling of gas diffusion to capillary electrophoresis, Talanta 45 (1998) 477-484, http://dx.doi.org/10.1016/S0039-9140(97)00131-8.

[44] P. Kubáň, B. Karlberg, Flow/sequential injection sample treatment coupled to capillary electrophoresis. A review, Anal. Chim. Acta 648 (2009) 129-145, http://dx. doi.org/10.1016/j.aca.2009.06.034.

[45] L.H.G. Coelho, I.G.R. Gutz, Automation of an analysis system with microvolume porous membrane sampling, capillary electrophoresis separation and contactless conductivity detection for near-real-time monitoring of traces of low-molecularweight carboxylic acids in air, J. Braz. Chem. Soc. 22 (2011) 2157-2164, http://dx doi.org/10.1590/S0103-50532011001100019.

[46] X.-Z. Wu, New approaches to sample preparation for capillary electrophoresis, TrAC Trends Anal. Chem. 22 (2003) 48-58, http://dx.doi.org/10.1016/S0165-9936(03) 00104-3.

[47] P.K. Tiwari, P. Sathe, N. Devadiga, Low level determination of genotoxic impurity in deferasirox formulation, J. Anal. Sci. Methods Instrum. 3 (2013) 179-183, http://dx.doi.org/10.4236/jasmi.2013.34023.

[48] Jonathan Clayden, N. Greeves, S. Warren, Organic Chemistry, 2nd ed., Oxford University Press, New York, 2012. 